\title{
CASE REPORT: A CONGENITAL ANOMALY OF THYROID GLAND WITH AGENESIS OF ISTHMUS AND PRESENCE OF PYRAMIDAL LOBE
}

\author{
I Anil Kumar ${ }^{1}$, Arindom Banerjee ${ }^{2}$, V. Harikrishna ${ }^{3}$
}

\section{HOW TO CITE THIS ARTICLE:}

I Anil Kumar, Arindom Banerjee, V Harikrishna. "Case report: a congenital anomaly of thyroid gland with agenesis of isthmus and presence of pyramidal lobe". Journal of Evolution of Medical and Dental Sciences 2013; Vol. 2, Issue 41, October 14; Page: 7899-7902.

\begin{abstract}
The thyroid gland is brownish-red and highly vascular gland which is placed anteriorly in the neck at the level of fifth cervical to the first thoracic vertebrae and is covered by the pretracheal layer of the deep cervical fascia. It has two lateral lobes which are connected by a narrow median isthmus giving an ' $\mathrm{H}$ ' shaped appearance to the gland. Congenital malformations and morphological variations of the thyroid gland are commonly reported in literature which has numerous clinical and surgical implications. In this case absence of isthmus was observed during routine dissection of a 60 yrs old male cadaver. The lateral lobes were positioned normally and a pyramidal lobe attached to the left lobe was seen. Moreover levator glandulae thyroideae extending from the hyoid bone to the apex of the pyramidal lobe was also observed. Agenesis of isthmus or presence of pyramidal lobe usually has no impact on thyroid functions and can be diagnosed by scintigraphy, ultrasonography, CT scan and MRI. However if the diagnoses is made during routine imaging or accidently, the patient must be thoroughly screened for other associated thyroid anomalies like autonomous thyroid nodule, thyroiditis, primary carcinoma, infiltrative diseases like amyloidoses etc.
\end{abstract}

KEY WORDS: (isthmus agenesis), (pyramidal lobe), (levator glandulae thyroideae), (congenital malformations)

INTRODUCTION: The thyroid gland, brownish-red and highly vascular, is a palpable endocrine gland placed anteriorly in the neck and its position extends from the fifth cervical to the first thoracic vertebrae. It is covered by the pre-tracheal layer of deep cervical fascia. The two lobes are connected by a narrow median isthmus. The normal size of each lobe of the thyroid gland has been described to be $5 \mathrm{~cm}$ long, its greatest transverse and antero-posterior extent being $3 \mathrm{~cm}$ and $2 \mathrm{~cm}$ respectively. The isthmus measures about $1.25 \mathrm{~cm}$ transversely as well as vertically and is usually placed anterior to the second and third tracheal cartilages ${ }^{1}$. The anomalies of the development of the thyroid gland distort the morphology of the gland, and may cause clinical functional disorders and various thyroid illnesses ${ }^{2}$. Besides, such anomalies can pose diagnostic and surgical challenges in addition to non-invasive and invasive airway management during emergency and surgical interventions ${ }^{3}$.

The incidence of isthmus agenesis varies from $5-10 \%{ }^{4}$. This absence can be explained as an anomaly of embryological development and can be associated with other types of dysorganogenesis, such as the absence of a lobe or the presence of ectopic thyroid tissue. Phylogenetically, in some species in which the thyroid follicles are organized in a gland, this gland can acquire a bi-lobed shape, in which the lobes join together in front of the upper part of the trachea by an isthmus or bridge of thyroid tissue. The isthmus may be missing, as happens in amphibians, birds and among the mammals, in the monotrema, certain marsupials, cetaceans, carnivores and rodents. 
It seems that these differences do not have an evolutionary origin, because the morphology does not result in any changes in thyroid function and, additionally, the follicular structure is similar in species that are distant from one another in taxonomic classifications ${ }^{5}$.

A conical pyramidal lobe often ascends towards the hyoid bone from the isthmus or the adjacent part of the either lobe. The levator of the thyroid gland-muscular levator glandulae thyroideae sometime descends from the hyoid body to the isthmus or pyramidal lobe6.

CASE REPORT: During routine dissection classes for $1^{\text {st }}$ M.B.B.S students in the Department of Anatomy at Konaseema Institute of Medical Sciences \& Research Foundation, Amalapuram, a 60 year old male cadaver showed the absence of Isthmus of the thyroid gland. In addition, a pyramidal lobe was also seen arising from the left lobe which was connected to the hyoid bone through a fibromuscular band of tissue which was attached to the tip of the pyramidal lobe. The two lobes of the thyroid gland were completely separate from each other and were normal in shape, size and position. There were no scar marks on the skin of the neck of the cadaver indicate of any operation performed in that region (e.g. Isthmusectomy). Each lateral lobe of thyroid gland was supplied by branches of superior and inferior thyroid arteries. There was no abnormality found in the blood supply of the gland. No accessory thyroid arteries were present.

DISCUSSION: Agenesis of the thyroid isthmus can also be defined as the complete and congenital absence of the thyroid isthmus. A wide range of morphological varieties and developmental anomalies of the thyroid gland have been reported in literature such as hypoplasia, ectopy, hemi agenesis etc, but incidence of agenesis of the isthmus of thyroid gland is rare and very few cases have been reported. It was reported as early as 1895 by Marshal ${ }^{7}$ where he found about 60 cases to be apparently abnormal. In $7 \%$ of cases, one lobe is markedly larger than the other. In six cases $(10 \%)$ isthmus was entirely absent. Absence of Isthmus of the thyroid gland was also reported in 1952 by Allan. He states that isthmus was absent in 2.0 to $4.0 \%$ of cases. He also observed that a band of connective tissue named levator glandulae thyroideae extended from the apex of right or left lobe or isthmus of the thyroid gland to the hyoid bone ${ }^{8}$. The presence of pyramidal process was also found in $43 \%$ cases by Marshall 7 in 1975 . The pyramidal process was sometimes found connected to the isthmus and to one of the lobes.

These congenital anomalies of the thyroid gland can be explained embryologically and few authors have stated the structural or functional alteration of chromosome number 22 resulting in thyroid lobar agenesis9.

The thyroid gland appears as an epithelial proliferation in the floor of the pharynx between tuberculum impar and the copula at a point later indicated by foramen caecum. Subsequently, thyroid gland descends in front of the pharyngeal gut as bi-lobed diverticulum. During this migration, the thyroid remains connected to the tongue by a narrow canal, the thyroglossal duct, this duct normally disappears ${ }^{10}$. Rarely, a high separation of thyroglossal duct can engender two independent thyroid lobes and pyramidal lobes with the absence of isthmus. During further development, the thyroid gland descends in front of the hyoid bone and the laryngeal cartilages. It reaches its final position in front of the trachea in the seventh week. The agenesis of isthmus of thyroid gland as noted may be due to a high separation of thyroglossal duct which can engender two independent thyroid lobes and pyramidal lobe with the absence of isthmus. Still the exact cause of 
hemi-agenesis is not clear and it is speculated the environmental and genetic factors may play a role in the development of this congenital anomaly.

CONCLUSION: Thyroid hem-agenesis is an asymptomatic condition which is usually diagnosed when the patient presents with other thyroid diseases. Agenesis of isthmus can be diagnosed via scintigraphy, ultrasonography, CT and MRI. Agenesis of isthmus can be associated with other types of dys-organogenesis, such as the absence of a lobe or the presence of ectopic thyroid tissue and hence in clinical practice when such a condition is diagnosed, it is necessary to perform a differential diagnosis against other pathologies such as autonomous thyroid nodule, thyroiditis, primary carcinoma, neoplastic metastases and infiltrative diseases such as amyloidosis ${ }^{11}$. When the condition is suspected it is necessary to perform an in-depth interview addressing previous surgical procedures in the cervical region (isthmectomy due to neoplasms, decompressive techniques due to thyroiditis or due to trans-thyroid tracheotomies).

Therefore a thorough knowledge of the thyroid anatomy and its associated anatomical variations is very much essential, so that these anomalies are not overlooked while treating patients with various thyroid diseases.

\section{REFERENCES:}

1. Rafiq A, Moore JA, Doarn CR, Merrell RC. Asynchronous confirmation of anatomical landmarks by optical capture in open surgery. Arch Surg 2003; 138:792-5.

2. Jain A, Pathak S. Rare developmental abnormalities of thyroid gland, especially multiple ectopias: A review and our experience. Indian J Nucl Med 2010; 25:143-6.

3. Kaur HS, Kumar U, Bajwa SJ, Kalyan GS. Absent thyroid isthmus: Embryological and clinical implications of a rare variation of thyroid gland revisited. Thyroid Res Pract [serial online] 2013 [cited 2013 Jun 22]; 10:80-2.

4. Pastor VJ, Gil VJ, De Paz Fernandez FJ, Cachorro MB. Agenesis of the thyroid isthmus. Eur J Anat 2006; 10:83-4.

5. Agenesis of the thyroid isthmus J.F. Pastor Vázquez, J.A. Gil Verona, F.J. De Paz Fernández and M. Barbosa Cachorro.

6. Williams PL, Bannister LK, Berry MM, Collins P, Dyson M, Dussek JE, Ferguson MWJ. Grays Anatomy. 38th Ed., Edinburgh, Churchill Livingstone. 2000: 1891-92.

7. Marshal 1895 variations in the form of the thyroid gland in man J. Anat Physiol 29:234.

8. Allan FD. An accessory or superficial inferior thyroid artery in a full term infant Anatomy. Rec 1952; 112: 53.

9. Gangbo E, Lancombe D, Alberti EM el al. Trisomy 22 with Thyroid Isthmus agenesis and absent gall bladder. Genet Couns 2004; 15: 311-5.

10. Sadler TW. Head and neck. Langman's Med Embryol 2006; 10: 270.

11. Pastur VJF, De paz Fernandez FJ, Cachorro MB. Agenesis of the thyroid isthmus. Eur J Anat 2006; 10: 83-4. 


\section{CASE REPORT}

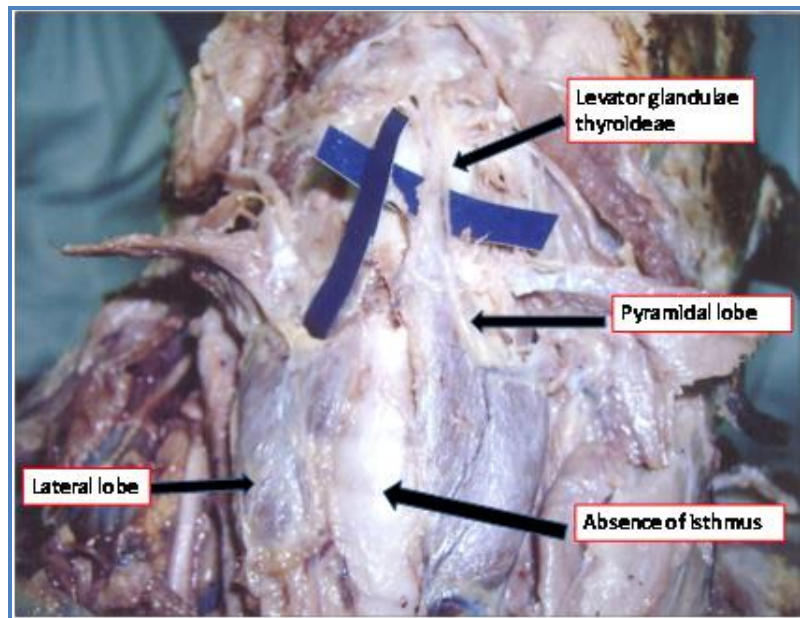

Figure 1: shows the absence of isthmus with the presence of pyramidal lobe arising from the left lateral lobe and levator glandulae thyroideae attaching it to the hyoid bone above.

\section{AUTHORS:}

1. I. Anil Kumar

2. Arindom Banerjee

3. V. Harikrishna

\section{PARTICULARS OF CONTRIBUTORS}

1. Assistant Professor, Department of Anatomy, Konaseema Institute of Medical Sciences and Research Foundation, Awalapuram.

2. Associate Professor, Department of Anatomy, Konaseema Institute of Medical Sciences and Research Foundation, Awalapuram.

3. Associate Professor, Department of Dental, Konaseema Institute of Medical Sciences and Research Foundation, Awalapuram.

\section{NAME ADDRESS EMAIL ID OF THE CORRESPONDING AUTHOR:}

Dr. Arindom Banerjee, Associate Professor, Department of Anatomy, KIMS \& RF, College Block, NH - 214, Awalapuram-214, PIN - 533201, A.P. Email - arindomdoc@yahoo.co.in

Date of Submission: 26/09/2013.

Date of Peer Review: 27/09/2013.

Date of Acceptance: 05/10/2013.

Date of Publishing: 09/10/2013 